\title{
Comparative analysis of Dimensions and Scopus bibliographic data sources: an approach to university research productivity
}

\author{
Pachisa Kulkanjanapiban', Tipawan Silwattananusarn ${ }^{2}$ \\ ${ }^{1}$ Khunying Long Athakravisunthorn Learning Resources Center, Prince of Songkla University, Hat Yai, Thailand \\ ${ }^{2}$ Information Management Program, Faculty of Humanities and Social Sciences, Prince of Songkla University, Pattani, Thailand
}

\begin{tabular}{l} 
Article Info \\
\hline Article history: \\
Received Mar 9, 2021 \\
Revised Jul 17, 2021 \\
Accepted Jul 28, 2021 \\
\hline
\end{tabular}

Keywords:

Citation analysis

Correlation study

Dimensions

Research productivity

Scopus

\begin{abstract}
This paper shows a significant comparison of two primary bibliographic data sources at the document level of Scopus and Dimensions. The emphasis is on the differences in their document coverage by institution level of aggregation. The main objective is to assess whether Dimensions offers at the institutional level good new possibilities for bibliometric analysis as at the global level. The results of a comparative study of the citation count profiles of articles published by faculty members of Prince of Songkla University (PSU) in Dimensions and Scopus from the year the databases first included PSU-authored papers (1970 and 1978, respectively) through the end of June 2020. Descriptive statistics and correlation analysis of 19,846 articles indexed in Dimensions and 13,577 indexed in Scopus. The main finding was that the number of citations received by Dimensions was highly correlated with citation counts in Scopus. Spearman's correlation between citation counts in Dimensions and Scopus was a high and mighty relationship. The findings mainly affect Dimensions' possibilities as instruments for carrying out bibliometric analysis of university members' research productivity. University researchers can use Dimensions to retrieve information, and the design policies can be used to evaluate research using scientific databases.
\end{abstract}

This is an open access article under the CC BY-SA license.

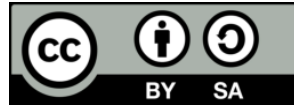

\section{Corresponding Author:}

Tipawan Silwattananusarn

Information Management Program, Faculty of Humanities and Social Sciences

Prince of Songkla University, Pattani Campus

181 Jalearnpradit Rd., Rusamilae, Muang Pattani 94000, Thailand

Email: tipawan.s@psu.ac.th

\section{INTRODUCTION}

There are recent examples of comprehensive literature comparing academic publication and/or citation coverage for the web of science and Scopus [1]-[14]. However, only a few recent studies have looked into the extent to which new sources of academic publication and citation data are covered by Dimensions [15]-[21]. For research evaluators, there are benefits of the existence of free online citation indexes: i) for many institutions that cannot afford to pay, free alternatives can reduce the cost of evaluations, ii) due to an imperfect of all citation indexes, the availability of alternatives allows data to be cross-checked against citation indexes, and iii) for impact evaluation task, each citation index may have coverage advantages that make it a better fit [21].

Researchers or institutions use citation counts to measure the impact of publications from the author's perspective [11] and evaluate the quality or impact of published research [21]. It is often taken for granted today that citations measure scientific impact and scientific quality in some way [22]-[24]. Citations are increasingly being used in research policy and the research system as performance indicators [25], [26]. 
Aksnes et al. [26] have investigated how citations may relate to various research quality and argued that citations reflect aspects of science's impact and relevance. Lambovsak and Yordanov [27] believe that the motivation of researchers to publish in high-quality journals is crucial to achieving the goals of researchers, universities, and society. The importance of citations for the researchers' reputation is one of the most important motivators for researchers' future publishing [28], [27]. This study analyses and compares Scopus and Dimensions' citations for selected publications output of Prince of Songkla University (PSU) faculty members. Comparing the citations from the two sources should help determine whether one source is better than another or whether a free database such as Dimensions could replace Scopus in PSU published works. Also, citations may be added as a new motivational driver to encourage PSU researchers to publish highquality journals.

Scopus is an abstract and citation database created by Elsevier in 2004; it is a bibliographic data source providing scientific documents and citation links. Scopus's significant feature is that all article types index all authors, institutional addresses, and bibliographic references for each article. Thus, to date, Scopus remains the leading source for citation data [9] and the most critical multidisciplinary bibliographic databases [12]. Some studies comparing Scopus and free citation databases are mainly focused on two aspects: i) the coverage of the databases and ii) impact at different levels, the accuracy of the databases, ranging from individual researchers to institutes [12], [29].

Dimensions, a free new online access scholarly search database platform for an analysis tool, was launched by Digital Science in January 2018. The links between grants, publications, clinical trials, patents, policy documents, and altimetric information, alongside traditional publications, and citation data, are core to Dimensions [18]; [19]. In September 2020, at the time of publication, the Dimensions database included over 112 million publications and their citations, content types, i.e., such as 582,398 clinical trials, 40 million patents, over 5 million grants, and 542,234 policy documents. The Dimensions platform makes available to research analysts, managers, and policy-makers [16]. Although the new-comer Dimensions was launched in 2018 , it is a strong rival of Scopus and is trying to challenge Scopus's dominant role. Only three published studies have investigated Dimensions' coverage and compared it to Scopus. Thelwall in study [21] showed that for publications in Food Science coverage and citation counts of Dimensions were comparable to Scopus's. Harzing [15] studied a detailed comparison across six data sources for an academic's complete publication and citation record in the field of Business and Economics. As demonstrated by Malea and Cózar [20] showed Dimensions' coverage analysis compared to Scopus and Google Scholar to determine whether Dimensions offered the bibliometric indicators have significant enough to be used. The results concluded that Dimensions has coverage of the recent literature superior to Scopus and the number of citations in Dimensions exhibited a strong correlation with Scopus. Also, Dimensions is an alternative for carrying out citation studies competing with Scopus in more generous coverage and free of charge [20]. Singh et al. [30] explored the Dimensions features and found two exciting features as a competitor to web of science and Scopus and research assessment. This study [30] has also shown that Dimensions may provide a ready-to-use mechanism for evaluators from a specific country to assess various institutions' research performance using their country journal lists. This study may also classify articles into various subject areas more precisely and subject-specific research performance evaluations more informed.

Dimensions was included in a recent study comparing various aspects until now of several old and new scholarly databases. Some comparative studies have analyzed Dimensions from a scientometric perspective [18]. However, no empirical study has been conducted focusing on citation analysis of PSU publications in Dimensions and Scopus in academic papers. Some questions are interesting for investigation: i) Is Dimensions threatening the dominating role of Scopus?; and ii) do the researchers from different countries and research fields have any preference in choosing these two databases?

Given Dimensions' potential utility in research assessments, it is critical to evaluate its fundamental properties to see if it has enough data to be valid and if its citation counts are accurate [21]. Thus, this study attempts to present an alternative approach to analyzing the two databases' journal coverage (Dimensions and Scopus). We used the direct comparison of overlapping in all two databases and analyzed the impact the coverage variations may have on academic research publication and citation record and affiliation searches in the field "Prince of Songkla University." The following characteristics are of particular interest: i) distribution of digital object identifier (DOIs) across sources, ii) differences recorded by each source in the year of publication, iii) citation counts calculated across sources, and iv) relationship of average citation counts in terms of Spearman's correlation. No study has compared PSU publications output in the two databases. This research aims to fill the gap across the study of PSU as depicted in reputed international university ranking systems. Moreover, to conduct a comparative and empirical analysis focusing on Dimensions and Scopus in PSU research outputs. 


\section{RESEARCH METHOD}

Statistical analysis and a descriptive-analytical method were used to conduct this study. Microsoft Excel software, SPSS, and R statistical programming language were used for data analysis and interpretations. Data were obtained by multiple Dimensions and Scopus searches as shown in Figure 1. Prince of Songkla University was used as a critical term in Dimensions' organization search field and Scopus's affiliation field. Advanced searches through different databases were used to find scholarly papers affiliated with the university. All publications affiliated to the Prince of Songkla University since the initial inclusion of PSU-authored publications were considered for study; there was no sampling. Each of the publications was analyzed for the authors' names and the number of authors and their affiliations.

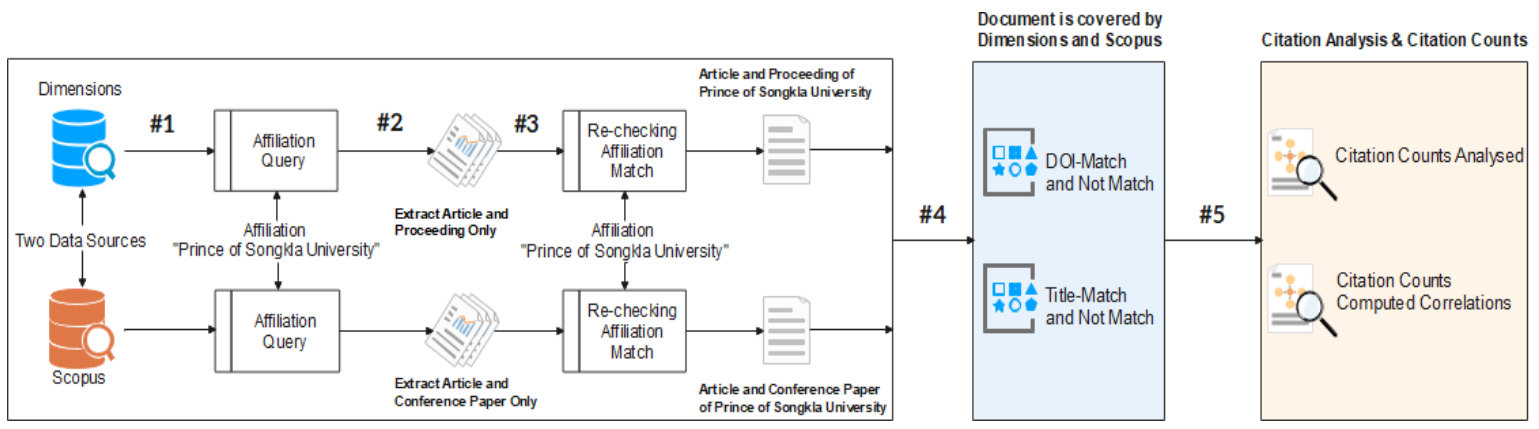

Figure 1. Visual representation of the documents and citation counts analyzed in this study

\subsection{Data collection}

There was no sampling procedure conducted in this study. By the end of June 2020, articles published in Dimensions and Scopus by scholars at Prince of Songkla University were investigated. The required data were collected from the Dimensions and the Scopus as shown in Table 1. To extract the required data, two significant steps are as follows:

Table 1. Number of documents retrieved by Scopus (1978-2020) and Dimensions (1970-2020)

\begin{tabular}{cccccc}
\hline \multicolumn{2}{c}{ Scopus (1978-2020) } & \multicolumn{4}{c}{ Dimensions (1970-2020) } \\
Document Types & No. of Documents & $\%$ & Document Types & No. of Documents & $\%$ \\
\hline Article & 11,487 & 84.61 & Article & 17,977 & 90.59 \\
Conference Paper & 1,430 & 10.53 & Proceedings & 845 & 4.26 \\
Review & 362 & 2.67 & Chapter & 654 & 3.29 \\
Book Chapter & 106 & 0.78 & Edited Book & 238 & 1.20 \\
Letter & 64 & 0.47 & Monograph & 67 & 0.34 \\
Note & 43 & 0.32 & Preprint & 64 & 0.32 \\
Erratum & 38 & 0.28 & Total & 19,846 & 100 \\
Editorial & 24 & 0.18 & & & \\
Short Survey & 11 & 0.08 & & & \\
Book & 3 & 0.02 & & & \\
Data Paper & 3 & 0.02 & & & \\
Undefined & 6 & 0.04 & & & \\
Total & 13,577 & 100 & &
\end{tabular}

\subsubsection{Data extraction from Dimensions}

Prince of Songkla University was searched into the search section based on Dimensions' organizational affiliation to extract the titles. Articles were reviewed due to the variety of writing styles among the writers. The study needs to identify those affiliated with the university. In the papers' availability, 18,822 documents of article and proceedings papers were added to the data extracted, see steps 1 and 2 in Figure 1. The data was cleaned again by examining the university's organizational affiliation (step 3 as shown in Figure 1) 11,412 documents.

\subsubsection{Data extraction from Scopus}

Research publications by PSU started to be indexed in Scopus in 1978. The literature data used in this study were collected using the Scopus database by searching in Scopus on June 30, 2020. The period time of this study was over 30-years period, 1978-2020, and the specifications searched: AFFILORG 
("Prince of Songkla University" 60006314) OR AF-ID ("Faculty of Medicine Prince of Songkia University" 60025527) AND (LIMIT-TO (DOCTYPE, “ar") OR LIMIT-TO (DOCTYPE, “cp"). This study brought the dataset to 12,917 documents that met the selection criteria (steps 1 and 2 in Figure 1). Review, book chapter, letter, note, erratum, editorial, short survey, and other document types were excluded. Each article's information was saved in an excel file [31] to be analyzed in the final stage. The extracted information includes title, authors, author's affiliations with Prince of Songkla University, year of publication, type of article, name of the journal, and the number of citations of each article.

\subsection{Objectives/research questions and statistical analysis}

There was no study comparing the productivity and impact of PSU researchers on Dimensions and Scopus. This research aimed to compare the coverage of Dimensions with the coverage of Scopus at the university level for research productivity. The questions posed were as follows:

a. RQ1: what is the trend of scholarly papers authored or co-authored indexed in Dimensions and Scopus?

b. RQ2: how much coverage is there between Dimensions and Scopus on articles with DOIs and citation data?

c. RQ3: are there any meaningful relationships in the average citation counts for educational documents in Dimensions comparable to Scopus?

d. RQ4: are citation counts of scholarly documents in Dimensions interchangeable with Scopus regarding having a too high correlation?

To reach this study's aims, descriptive statistics, i.e., geometric mean, exponential regression test, and correlation test, were used to analyze data in Excel and R version 4.0.2. To respond to RQ1, the document types and citation count of the citing documents in our sample (step 4 in Figure 1) were aggregated or averaged by differentiating between unique Dimensions citations and overlapping citations. To reply to RQ2, Dimensions' coverage was compared to Scopus by measuring the percentage of Scopus documents with DOI that were also in Dimensions per year (step 4 in Figure 1). Moreover, report the size of the overlaps. Additionally, the causes of why these documents were not covered are provided. Publications before 1985 were not considered because of the limited coverage of these publications in Dimensions. The citing documents from both were matched to gather and compute citation overlaps from two different data sets (Dimensions and Scopus). The matching process started with attempting to match publications based on DOI. If no DOI-based match could be obtained, a match was attempted for the title's name. To answer RQ3, the geometric mean citation counts for Dimensions for each year were compared against Scopus. The geometric mean is stronger than the arithmetic mean because citation data is highly skewed [21]. To answer $\mathrm{RQ} 4$, Spearman correlation coefficients were calculated for the citation counts of the citing documents in our sample (step 5 in Figure 1). In this case, citation counts from Dimensions and Scopus were compared for each year using Spearman correlations. For data not found in Dimensions, with and without articles, the correlations were calculated as for RQ3. The raw data, custom functions in Excel, the R code, and several R packages were used for the analysis to carry out all these processes.

\section{RESULTS AND DISCUSSION}

\subsection{What is the trend of scholarly papers authored or co-authored indexed in Dimensions and Scopus?}

The total scholarly papers by faculty members of Prince of Songkla University are shown in Table 2, Figure 2, and Figure 3 by year of publication and growth rate. Publications by authors from Prince of Songkla University first appeared in Dimensions in 1970 and 1978 in Scopus. Over the period under consideration, 11,412 documents in Dimensions and 12,915 in Scopus were published by PSU researchers. According to Table 1, 1,503 more publications were indexed by Scopus than were by Dimensions. The number of papers included was low until 1985; the publications' rate has since increased regularly. A similar growth rate was found in both databases, especially in the later years. An exponential function can describe the yearly growth rate of publications: $y=a e^{b t}$, where $a$ is a constant value, $b$ is the growth rate of publications in $t$ (year), and e is the natural foundation logarithm. $R^{2}$ for a nonlinear least-squares regression shows the test results' significance level. As shown in Figure 2, over the years examined, the number of PSU publications has increased. A $15.32 \%$ growth rate for PSU publications in Dimensions and a $14.85 \%$ growth rate in Scopus were shown in the exponential regression report. Comparing the two databases shows that the increase rate (exponential trend line) in both data sources is almost identical. Overall, the number of PSU's publications in Scopus is about 1.13 times higher than that of Dimensions. However, the number of publications is ascending equally in both databases over the last twenty years.

Based on the results in Table 2 and Figure 3, PSU publications in Scopus $(168,082)$ have received more citations than Dimensions' publications $(152,397)$. However, the number of citations per publication is 
slightly higher in Dimensions (13.35) than in Scopus (13.01). This finding is consistent with that of [30] reported a higher cited value for Scopus than Dimensions.

Based on the findings in Table 3 and Figure 4, the number of cited publications in Dimension and Scopus is rising over the years but not in recent years. The results showed that in Scopus, the number of cited publications is slightly higher than in Dimensions. About $79.14 \%$ of the total PSU publications in Scopus are cited, while this percentage in Dimensions is about 78.29\%. Some papers have never been cited. This status is referred to as a non-cited publication that shows the number of publications that do not affect their associated community. As shown in Figure 4, the number of non-cited publications is growing in both databases. The counts of Table 3 revealed that the number of non-cited PSU publications is slightly higher in Dimensions than Scopus. In 2016, about $87.31 \%$ of Dimensions publications were cited, and about $12.69 \%$ were non-cited. Overall, about $21.71 \%$ of total publications in Dimensions are non-cited, while this percentage in Scopus is about $20.86 \%$.

Table 2. Publications and citations by scholars in Dimensions (1970-2020) and Scopus (1978-2020)

\begin{tabular}{|c|c|c|c|c|c|c|c|}
\hline \multicolumn{4}{|c|}{ Dimensions (1970-2020) } & \multicolumn{4}{|c|}{ Scopus (1978-2020) } \\
\hline Year & $\begin{array}{c}\text { No. of } \\
\text { Publications }\end{array}$ & $\begin{array}{c}\text { No. of } \\
\text { Citations }\end{array}$ & $\begin{array}{l}\text { Citations per } \\
\text { Publication }\end{array}$ & Year & $\begin{array}{c}\text { No. of } \\
\text { Publications }\end{array}$ & $\begin{array}{c}\text { No. of } \\
\text { Citations }\end{array}$ & $\begin{array}{c}\text { Citations per } \\
\text { Publication }\end{array}$ \\
\hline 1970 & 1 & 0 & - & 1970 & - & - & - \\
\hline 1971 & 0 & 0 & 0 & 1971 & - & - & - \\
\hline 1973 & 1 & 4 & 4.00 & 1973 & - & - & - \\
\hline 1974 & 0 & 0 & 0.00 & 1974 & - & - & - \\
\hline 1975 & 0 & 0 & 0.00 & 1975 & - & - & - \\
\hline 1976 & 0 & 0 & 0.00 & 1976 & - & - & - \\
\hline 1977 & 0 & 0 & 0.00 & 1977 & - & - & - \\
\hline 1978 & 2 & 25 & 12.50 & 1978 & 2 & 18 & 9.00 \\
\hline 1979 & 0 & 0 & 0.00 & 1979 & 2 & 27 & 13.50 \\
\hline 1980 & 7 & 63 & 9.00 & 1980 & 11 & 76 & 6.91 \\
\hline 1981 & 1 & 19 & 19.00 & 1981 & 4 & 32 & 8.00 \\
\hline 1982 & 4 & 60 & 15.00 & 1982 & 6 & 59 & 9.83 \\
\hline 1983 & 2 & 16 & 8.00 & 1983 & 8 & 27 & 3.38 \\
\hline 1984 & 0 & 0 & 0.00 & 1984 & 4 & 3 & 0.75 \\
\hline 1985 & 3 & 2 & 0.67 & 1985 & 5 & 46 & 9.20 \\
\hline 1986 & 7 & 100 & 14.29 & 1986 & 10 & 132 & 13.20 \\
\hline 1987 & 9 & 35 & 3.89 & 1987 & 14 & 221 & 15.79 \\
\hline 1988 & 7 & 126 & 18.00 & 1988 & 8 & 143 & 17.88 \\
\hline 1989 & 11 & 207 & 18.82 & 1989 & 15 & 240 & 16.00 \\
\hline 1990 & 35 & 317 & 9.06 & 1990 & 37 & 365 & 9.86 \\
\hline 1991 & 36 & 409 & 11.36 & 1991 & 37 & 490 & 13.24 \\
\hline 1992 & 27 & 174 & 6.44 & 1992 & 29 & 218 & 7.52 \\
\hline 1993 & 45 & 445 & 9.89 & 1993 & 49 & 553 & 11.29 \\
\hline 1994 & 32 & 627 & 19.59 & 1994 & 40 & 906 & 22.65 \\
\hline 1995 & 43 & 913 & 21.23 & 1995 & 46 & 1,157 & 25.15 \\
\hline 1996 & 40 & 1,172 & 29.30 & 1996 & 56 & 1,572 & 28.07 \\
\hline 1997 & 78 & 1,183 & 15.17 & 1997 & 87 & 2,211 & 25.41 \\
\hline 1998 & 66 & 1,529 & 23.17 & 1998 & 83 & 2,048 & 24.67 \\
\hline 1999 & 88 & 1,682 & 19.11 & 1999 & 99 & 2,258 & 22.81 \\
\hline 2000 & 103 & 2,166 & 21.03 & 2000 & 111 & 2,504 & 22.56 \\
\hline 2001 & 123 & 1,982 & 16.11 & 2001 & 114 & 2,235 & 19.61 \\
\hline 2002 & 134 & 3,713 & 27.71 & 2002 & 135 & 4,166 & 30.86 \\
\hline 2003 & 157 & 3,680 & 23.44 & 2003 & 166 & 4,510 & 27.17 \\
\hline 2004 & 173 & 4,592 & 26.54 & 2004 & 159 & 5,414 & 34.05 \\
\hline 2005 & 247 & 6,147 & 24.89 & 2005 & 251 & 7,148 & 28.48 \\
\hline 2006 & 319 & 8,591 & 26.93 & 2006 & 389 & 9,838 & 25.29 \\
\hline 2007 & 372 & 8,698 & 23.38 & 2007 & 504 & 9,459 & 18.77 \\
\hline 2008 & 458 & 9,756 & 21.30 & 2008 & 568 & 11,408 & 20.08 \\
\hline 2009 & 417 & 14,410 & 34.56 & 2009 & 487 & 16,075 & 33.01 \\
\hline 2010 & 471 & 9,997 & 21.23 & 2010 & 559 & 11,291 & 20.20 \\
\hline 2011 & 543 & 11,365 & 20.93 & 2011 & 650 & 12,479 & 19.20 \\
\hline 2012 & 645 & 11,225 & 17.40 & 2012 & 736 & 12,311 & 16.73 \\
\hline 2013 & 750 & 9,348 & 12,46 & 2013 & 850 & 9,702 & 11.41 \\
\hline 2014 & 722 & 8,922 & 12.36 & 2014 & 853 & 9,684 & 11.35 \\
\hline 2015 & 716 & 8,925 & 12.47 & 2015 & 806 & 8,980 & 11.14 \\
\hline 2016 & 725 & 7,480 & 10.32 & 2016 & 849 & 6,819 & 8.03 \\
\hline 2017 & 936 & 6,040 & 6.45 & 2017 & 1,006 & 5,635 & 5.60 \\
\hline 2018 & 990 & 3,956 & 4.00 & 2018 & 1,133 & 3,592 & 3.17 \\
\hline 2019 & 1,094 & 2,015 & 1.84 & 2019 & 1,230 & 1,838 & 1.49 \\
\hline 2020 & 772 & 281 & 0.36 & 2020 & 707 & 192 & 0.27 \\
\hline Total & 11,412 & 152,397 & 13.35 & Total & 12,915 & 168,082 & 13.01 \\
\hline
\end{tabular}




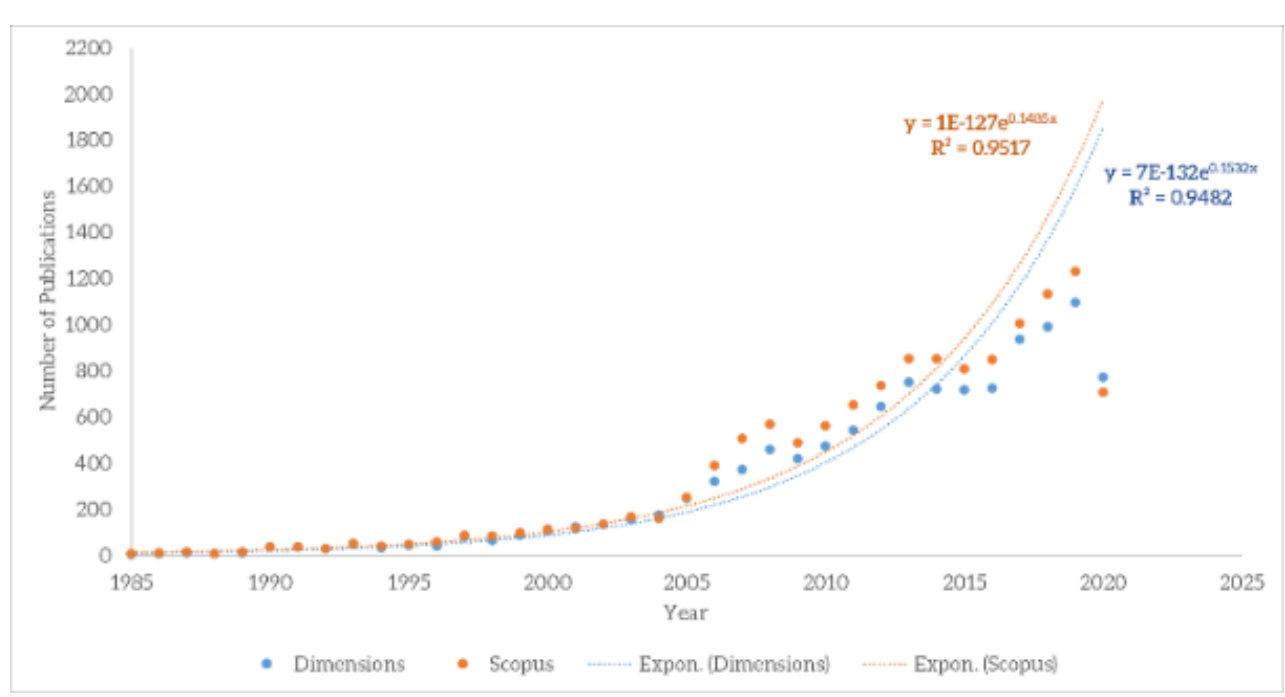

Figure 2. The growth rate of scholarly publications in Dimensions vs Scopus

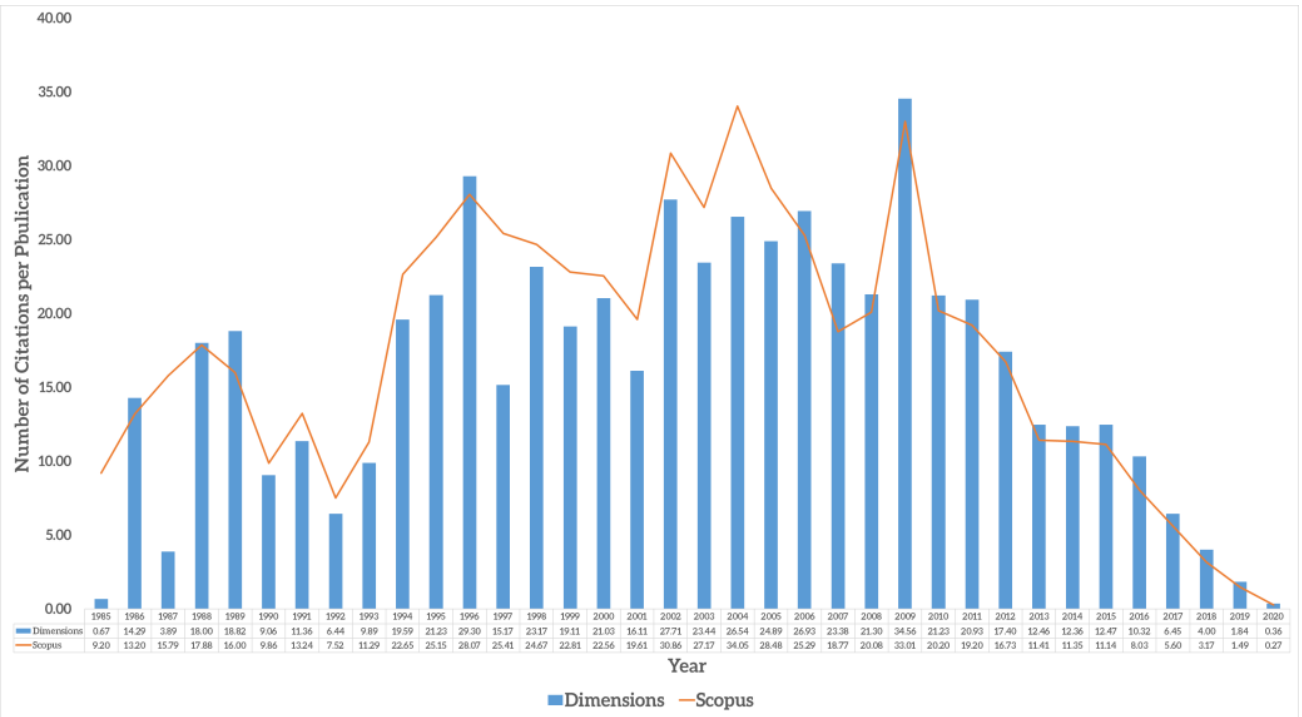

Figure 3. Number of citations per publication in Dimensions vs Scopus

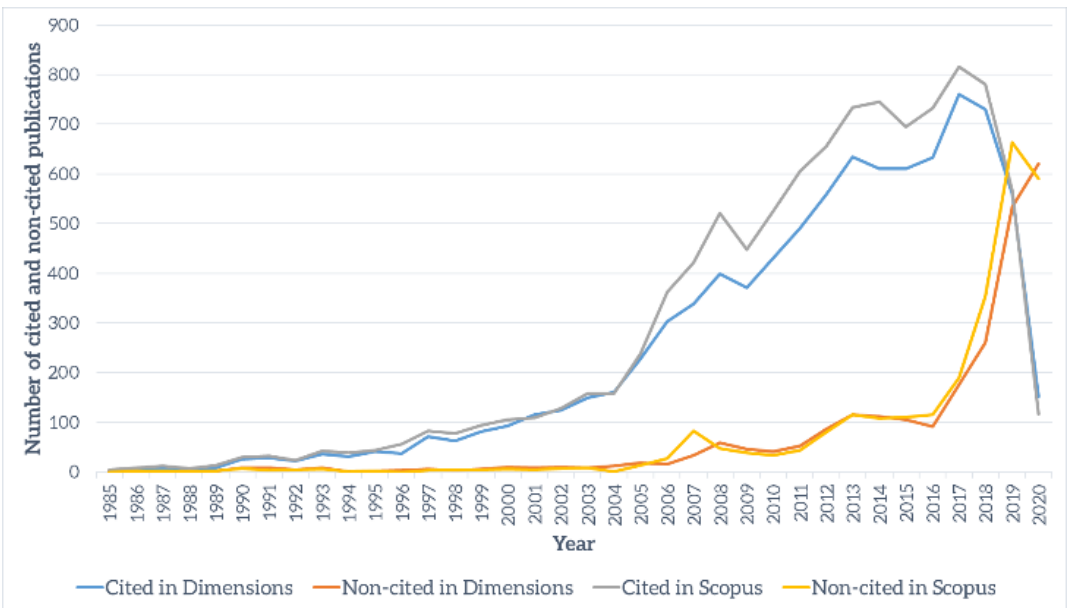

Figure 4. Number of cited and non-cited publications in Dimensions vs Scopus 
Table 3. Number and percentage of cited and non-cited publications by scholars in Dimensions (1970-2020) and Scopus

\begin{tabular}{|c|c|c|c|c|c|c|c|c|c|}
\hline \multicolumn{10}{|c|}{ Dimensions (1970-2020) } \\
\hline Year & $\begin{array}{c}\text { Cited } \\
\text { publication }\end{array}$ & $\begin{array}{c}\% \text { of the } \\
\text { total } \\
\text { publication }\end{array}$ & $\begin{array}{l}\text { Non-cited } \\
\text { publication }\end{array}$ & $\begin{array}{c}\% \text { of the } \\
\text { total } \\
\text { publication }\end{array}$ & Year & $\begin{array}{c}\text { Cited } \\
\text { publication }\end{array}$ & $\begin{array}{c}\% \text { of the } \\
\text { total } \\
\text { publication }\end{array}$ & $\begin{array}{l}\text { Non-cited } \\
\text { publication }\end{array}$ & $\begin{array}{c}\% \text { of the } \\
\text { total } \\
\text { publication }\end{array}$ \\
\hline 1970 & 0 & 0.00 & 1 & 100.00 & 1970 & - & - & - & - \\
\hline 1971 & 0 & 0.00 & 0 & 0.00 & 1971 & - & - & - & - \\
\hline 1972 & 0 & 0.00 & 0 & 0.00 & 1972 & - & - & - & - \\
\hline 1973 & 1 & 100.00 & 0 & 0.00 & 1973 & - & - & - & - \\
\hline 1974 & 0 & 0.00 & 0 & 0.00 & 1974 & - & - & - & - \\
\hline 1975 & 0 & 0.00 & 0 & 0.00 & 1975 & - & - & - & - \\
\hline 1976 & 0 & 0.00 & 0 & 0.00 & 1976 & - & - & - & - \\
\hline 1977 & 0 & 0.00 & 0 & 0.00 & 1977 & - & - & - & - \\
\hline 1978 & 2 & 100.00 & 0 & 0.00 & 1978 & 2 & 100.00 & 0 & 0.00 \\
\hline 1979 & 0 & 0.00 & 0 & 0.00 & 1979 & 2 & 100.00 & 0 & 0.00 \\
\hline 1980 & 7 & 100.00 & 0 & 0.00 & 1980 & 11 & 100.00 & 0 & 0.00 \\
\hline 1981 & 1 & 100.00 & 0 & 0.00 & 1981 & 4 & 100.00 & 0 & 0.00 \\
\hline 1982 & 3 & 75.00 & 1 & 25.00 & 1982 & 5 & 83.33 & 1 & 16.67 \\
\hline 1983 & 1 & 50.00 & 1 & 50.00 & 1983 & 5 & 62.50 & 3 & 37.50 \\
\hline 1984 & 0 & 0.00 & 0 & 0.00 & 1984 & 2 & 50.00 & 2 & 50.00 \\
\hline 1985 & 2 & 66.67 & 1 & 33.33 & 1985 & 5 & 100.00 & 0 & 0.00 \\
\hline 1986 & 6 & 85.71 & 1 & 14.29 & 1986 & 8 & 80.00 & 2 & 20.00 \\
\hline 1987 & 8 & 88.89 & 1 & 11.11 & 1987 & 12 & 85.71 & 2 & 14.29 \\
\hline 1988 & 6 & 85.71 & 1 & 14.29 & 1988 & 7 & 87.50 & 1 & 12.50 \\
\hline 1989 & 9 & 81.82 & 2 & 18.18 & 1989 & 13 & 86.67 & 2 & 13.33 \\
\hline 1990 & 26 & 74.29 & 9 & 25.71 & 1990 & 30 & 81.08 & 7 & 18.92 \\
\hline 1991 & 28 & 77.78 & 8 & 22.22 & 1991 & 33 & 89.19 & 4 & 10.81 \\
\hline 1992 & 22 & 81.48 & 5 & 18.52 & 1992 & 24 & 82.76 & 5 & 17.24 \\
\hline 1993 & 36 & 80.00 & 9 & 20.00 & 1993 & 43 & 87.76 & 6 & 12.24 \\
\hline 1994 & 31 & 96.88 & 1 & 3.13 & 1994 & 39 & 97.50 & 1 & 2.50 \\
\hline 1995 & 41 & 95.35 & 2 & 4.65 & 1995 & 44 & 95.65 & 2 & 4.35 \\
\hline 1996 & 37 & 92.50 & 3 & 7.50 & 1996 & 56 & 100.00 & 0 & 0.00 \\
\hline 1997 & 72 & 92.31 & 6 & 7.69 & 1997 & 83 & 95.40 & 4 & 4.60 \\
\hline 1998 & 62 & 93.94 & 4 & 6.06 & 1998 & 78 & 93.98 & 5 & 6.02 \\
\hline 1999 & 82 & 93.18 & 6 & 6.82 & 1999 & 94 & 94.95 & 5 & 5.05 \\
\hline 2000 & 93 & 90.29 & 10 & 9.71 & 2000 & 105 & 94.59 & 6 & 5.41 \\
\hline 2001 & 115 & 93.50 & 8 & 6.50 & 2001 & 109 & 95.61 & 5 & 4.39 \\
\hline 2002 & 124 & 92.54 & 10 & 7.46 & 2002 & 128 & 94.81 & 7 & 5.19 \\
\hline 2003 & 149 & 94.90 & 8 & 5.10 & 2003 & 158 & 95.18 & 8 & 4.82 \\
\hline 2004 & 161 & 93.06 & 12 & 6.94 & 2004 & 158 & 99.37 & 1 & 0.63 \\
\hline 2005 & 228 & 92.31 & 19 & 7.69 & 2005 & 238 & 94.82 & 13 & 5.18 \\
\hline 2006 & 303 & 94.98 & 16 & 5.02 & 2006 & 362 & 93.06 & 27 & 6.94 \\
\hline 2007 & 338 & 90.86 & 34 & 9.14 & 2007 & 421 & 83.53 & 83 & 16.47 \\
\hline 2008 & 399 & 87.12 & 59 & 12.88 & 2008 & 521 & 91.73 & 47 & 8.27 \\
\hline 2009 & 371 & 88.97 & 46 & 11.03 & 2009 & 448 & 91.99 & 39 & 8.01 \\
\hline 2010 & 430 & 91.30 & 41 & 8.70 & 2010 & 525 & 93.92 & 34 & 6.08 \\
\hline 2011 & 491 & 90.42 & 52 & 9.58 & 2011 & 606 & 93.23 & 44 & 6.77 \\
\hline 2012 & 559 & 86.67 & 86 & 13.33 & 2012 & 656 & 89.13 & 80 & 10.87 \\
\hline 2013 & 635 & 84.67 & 115 & 15.33 & 2013 & 734 & 86.35 & 116 & 13.65 \\
\hline 2014 & 610 & 84.49 & 112 & 15.51 & 2014 & 745 & 87.34 & 108 & 12.66 \\
\hline 2015 & 610 & 85.20 & 106 & 14.80 & 2015 & 695 & 86.23 & 111 & 13.77 \\
\hline 2016 & 633 & 87.31 & 92 & 12.69 & 2016 & 733 & 86.34 & 116 & 13.66 \\
\hline 2017 & 760 & 81.20 & 176 & 18.80 & 2017 & 816 & 81.11 & 190 & 18.89 \\
\hline 2018 & 730 & 73.74 & 260 & 26.26 & 2018 & 780 & 68.84 & 353 & 31.16 \\
\hline 2019 & 560 & 51.19 & 534 & 48.81 & 2019 & 566 & 46.02 & 664 & 53.98 \\
\hline 2020 & 152 & 19.69 & 620 & 80.31 & 2020 & 117 & 16.55 & 590 & 83.45 \\
\hline Total & 8934 & 78.29 & 2478 & 21.71 & Total & 10221 & 79.14 & 2694 & 20.86 \\
\hline
\end{tabular}

\subsection{How much coverage is there between Dimensions and Scopus on articles with DOIs and citation data?}

To assess the extent to which the Dimensions and Scopus coverage overlap, each scholarly document was classified in the three following categories: Dimensions only (educational documents that are indexed in Dimensions but not in Scopus), overlap (educational documents that are indexed in both Dimensions and Scopus), and Scopus only (educational documents that are indexed in Scopus but not in Dimensions). Figure 5(a) shows that out of the 12,915 documents displayed in Scopus, 1,559 (12.07\%) were not covered in Dimensions. In contrast, 3,062 (26.83\%) of the 11,412 documents were displayed in Dimensions but not covered in Scopus. Among these, 9,853 documents were covered in Dimensions and Scopus: 9,357 documents with a DOI-based match and 496 documents with a title-based match. In total, 
3,062 documents were not covered by Dimensions. Among these, 1,043 were DOI-based matches, and 2,019 were title-based matches in Scopus.

Regarding these 1,559 documents, 1,500 documents were DOI-based matches, and 59 documents were title-based matches covered by Dimensions. Figure 5(b) shows that out of 168,082 citation counts in Scopus and 152,397 in Dimensions, 19,105 citation counts were not covered, and 13,236 citation counts were not covered in Scopus. Also, there was 148,977 coverage of citation counts in Scopus, and 139,161 coverage of citation counts in Dimensions in the two databases overlap.

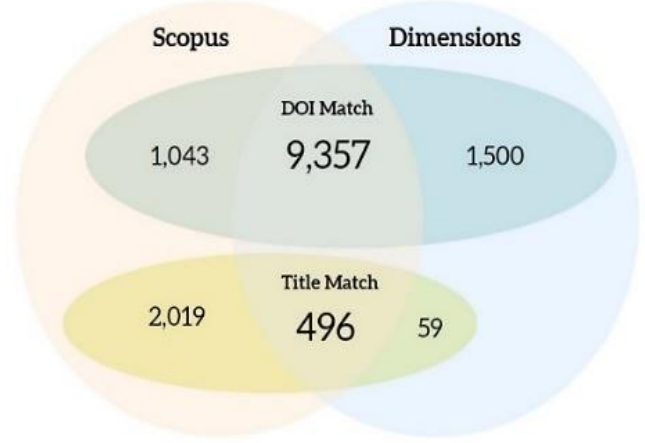

(a)

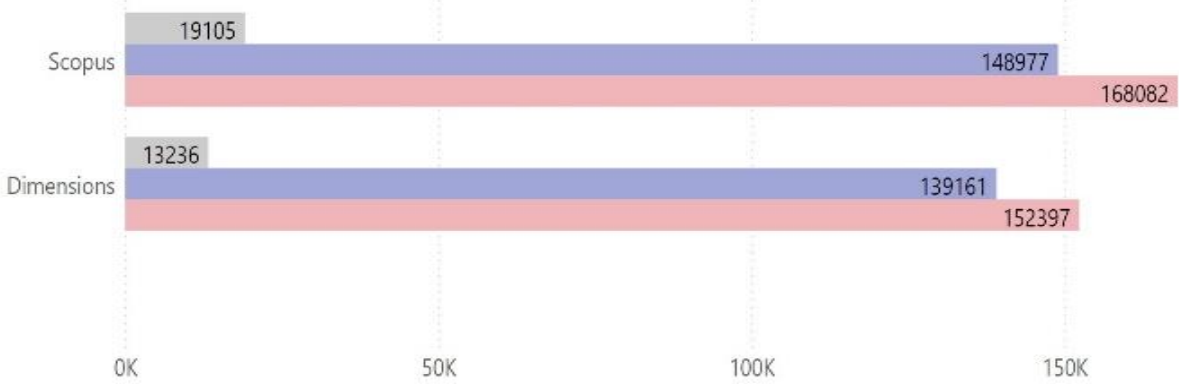

(b)

Figure 5. The number of coverages in Dimensions and Scopus by: (a) articles with DOIs, (b) articles with citation counts

Dimensions and Scopus's significant differences in coverage were found across the year publication as shown in Figure 6. More documents were missing from Dimensions than Scopus in the year 1985 (28.5\% in Dimensions, 57.14\% in Scopus), the year 1987 (6.67\% in Dimensions, 40.0\% in Scopus), the year 1996 (9.68\% in Dimensions, 35.48\% in Scopus) and the year 2007 (8.53\% in Dimensions, and 32.49\% in Scopus). Moreover, Dimensions seemed to be missing documents in 2006 (6.94\%) and 2016 (8.51\%). However, the coverage of these three years, i.e., the year 2020, the year 2004, and 2001 in Dimensions, seemed to be better $(20.11 \%, 17.62 \%$, and $17.99 \%$ missing documents, respectively). Additionally, from 1985 to 2020 , the average percentage of document coverage overlap in Dimensions and Scopus was 66.8575\%.

In Figure 7, for the number of citations counts in overlap documents, the percentage of average citation counts in Scopus was $44.05 \%$ (in light orange color). The average citation counts in Dimensions were $40.78 \%$ (light blue). These findings seemed that the percentage of citation counts coverage overlap in Scopus was much higher than Dimensions (3.27\%). The percentages of citation count in Scopus were higher than Dimensions in the year 1985 (91.67\%), the year 1987 (70.70\%), and the year $1997(25.84 \%)$ respectively (in dark orange color). The result showed that Dimensions seemed not to index impact articles highly. However, the differences in percentages of citation count in Dimensions were higher than Scopus during 2016 to 2020 with $4.59 \%, 4.36 \%, 3.20 \%, 2.39 \%$, and 5.92\%, respectively (in dark blue color). These findings displayed that Scopus seemed to missing index impact articles. 
Scopus Only Overlap Dimensions Only

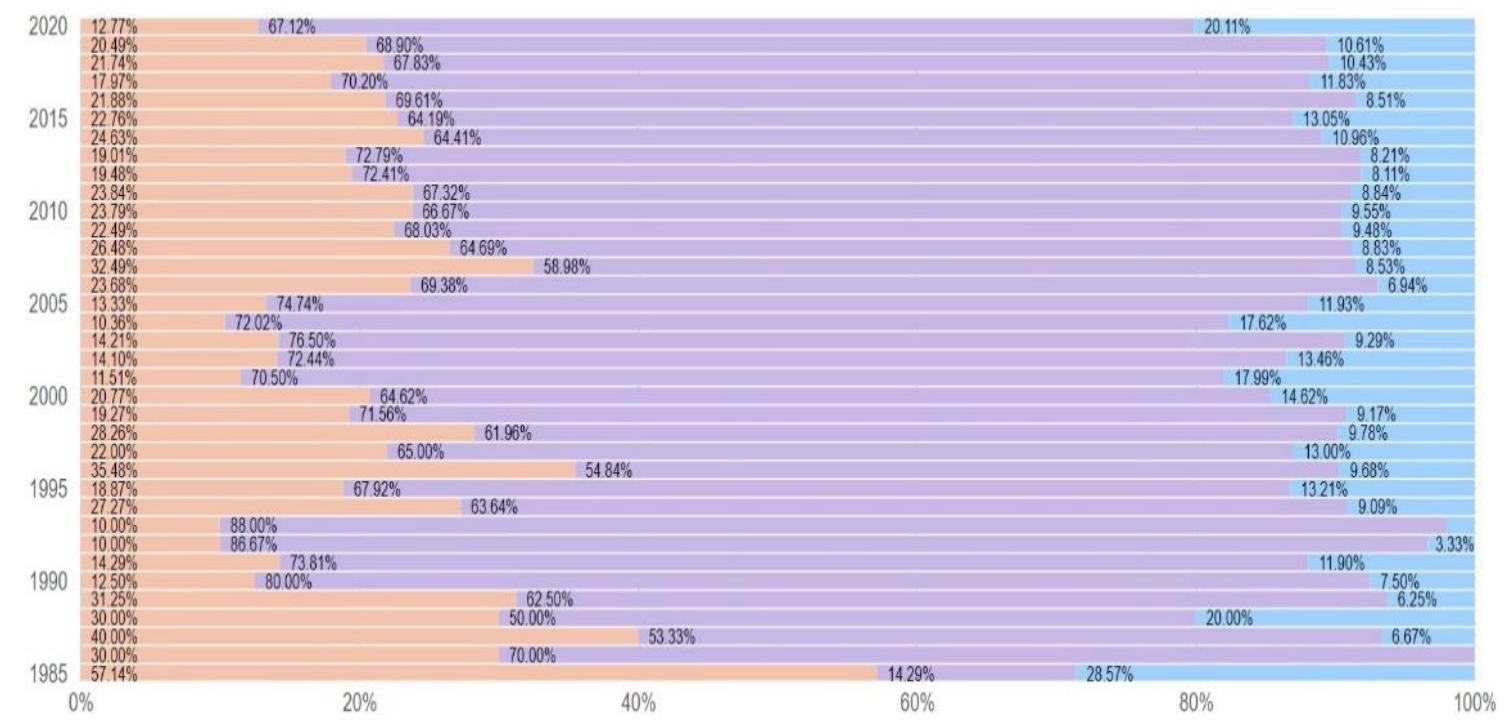

Figure 6. Document's coverage overlaps in Dimensions and Scopus by year publication

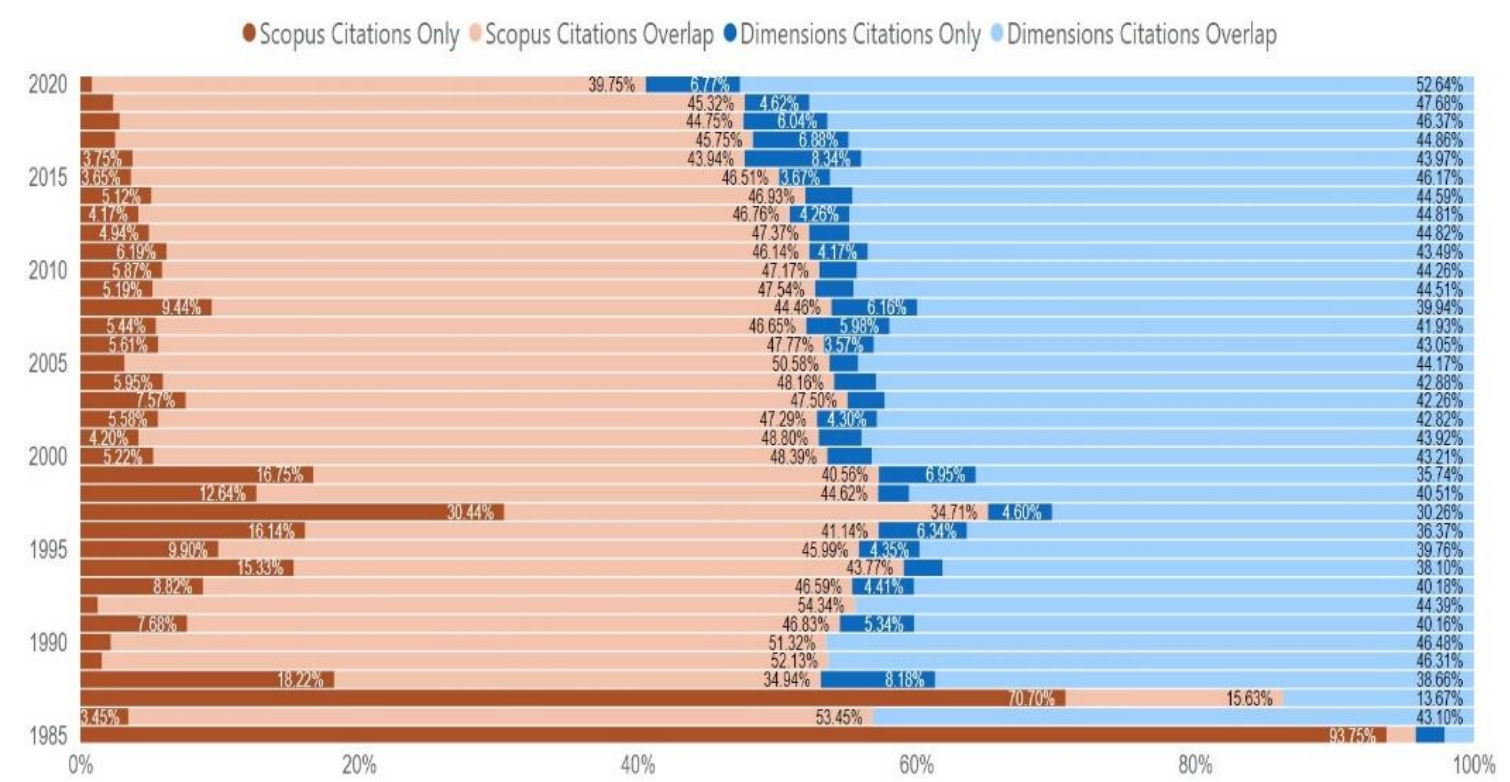

Figure 7. Citation counts coverage overlap in Dimensions and Scopus by year publication

Among the causes of citation, documents were not covered in Dimensions and Scopus as shown in Table 4; the most frequent was that the journal where the documents were published was not covered in key term search (36.80\%). 35.60\% of the missing DOI documents in Dimensions did not index in Scopus, and $22.78 \%$ of the most DOI-based unmatched documents were found in Scopus but were not indexed in Dimensions. Documents were being indexed in journals, but coverage was missing from the database $(2.87 \%)$ or the source title missing $(3.33 \%)$. The findings found many articles in Dimensions for which there was no matching document in the matching procedure. Dimensions appear that any document published in a journal is classified as an article [32]. Scopus consistently contains more records and citations than Dimensions as documents are aggregated by institutional association [33]. Although Dimensions and Scopus contain errors such as duplicate documents and citations, incomplete and incorrect bibliographic information [9], [21], these issues do not seem to be a problem for this study because the authors justify dismissing citation counts as unreliable on account of the bibliographic errors present in Dimensions and Scopus. 
Table 4. Causes of documents not being matched in Dimensions and Scopus

\begin{tabular}{|c|c|c|c|c|}
\hline Causes & $\mathrm{N}$ & Examples of Journal & $\mathrm{n}$ & $\%$ \\
\hline \multirow[t]{2}{*}{$\begin{array}{l}\text { Search for organizational affiliation in } \\
\text { Dimensions but found irrelevant data }\end{array}$} & 7,410 & $\begin{array}{c}\text { The documents indexed in Critical Care in } \\
\text { Dimensions }\end{array}$ & 2,727 & 36.80 \\
\hline & & $\begin{array}{c}\text { The documents indexed in Tobacco Induced } \\
\text { Diseases }\end{array}$ & 964 & 13.00 \\
\hline \multirow{2}{*}{$\begin{array}{c}\text { The most DOI-based unmatched documents } \\
\text { were found in Scopus but not indexed in } \\
\text { Dimensions }\end{array}$} & 2,019 & $\begin{array}{l}\text { Found in Songklanakarin Journal of Science and } \\
\text { Technology }\end{array}$ & 460 & 22.78 \\
\hline & & $\begin{array}{c}\text { Found in Journal of Medical Association of } \\
\text { Thailand }\end{array}$ & 222 & 11.00 \\
\hline $\begin{array}{l}\text { Documents with no DOI-based match in } \\
\text { Dimensions were not indexed in Scopus }\end{array}$ & 59 & $\begin{array}{c}\text { Found in Journal of the Medical Association of } \\
\text { Thailand (Chot Mai Het Thang Phaet) }\end{array}$ & 21 & 35.60 \\
\hline $\begin{array}{l}\text { The Dimensions database did not cover } \\
\text { documents }\end{array}$ & 1,043 & $\begin{array}{l}\text { Found in Songklanakarin Journal of Science and } \\
\text { Technology }\end{array}$ & 80 & 7.67 \\
\hline \multirow{4}{*}{$\begin{array}{c}\text { Documents were being indexed, but coverage } \\
\text { was incomplete (some source title, volume, or } \\
\text { issues were missing) }\end{array}$} & & Found in ScienceAsia & 67 & 6.42 \\
\hline & & Found in Asian Social Science & 57 & 5.47 \\
\hline & 1,500 & The source title was missing & 50 & 3.33 \\
\hline & & Found in ChemInform & 43 & 2.87 \\
\hline
\end{tabular}

\subsection{Are there any meaningful relationships in the average citation counts for educational documents in Dimensions comparable to Scopus?}

This section analyzed any relationships in the average citation counts of the 152,397 citation counts in Dimensions versus the 168,082 citation counts in Scopus, and the 139,161 citing documents match extracted from Dimensions and 148,977 citing documents match extracted from Scopus. Citation counts of Scopus documents are higher than citation counts in Dimensions as shown in Figure 8(a) and (b). The results showed that geometric mean citation counts are approximately the same as Scopus citation counts for Dimensions documents to answer this research question as shown in Figure 8(b).

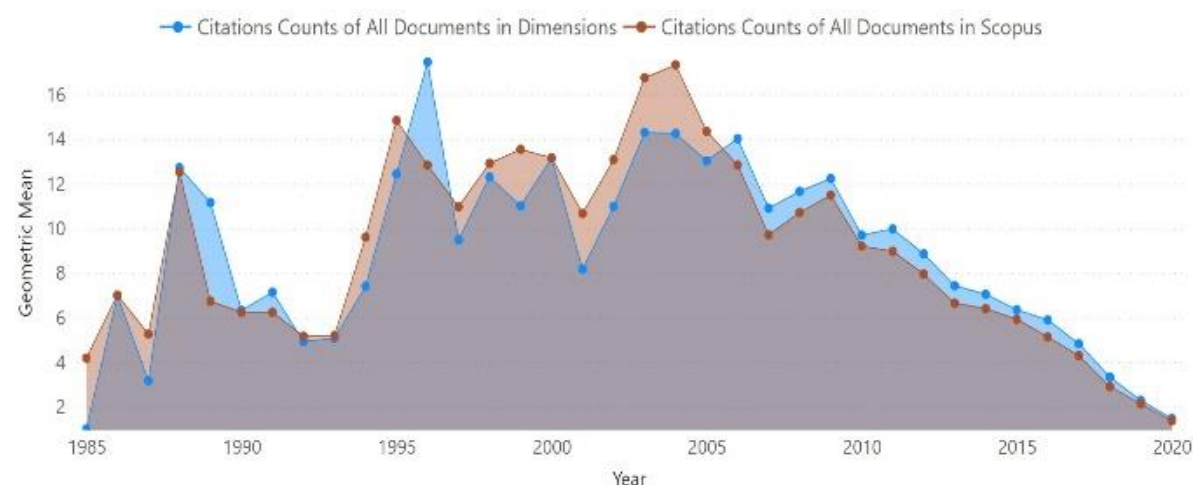

(a)

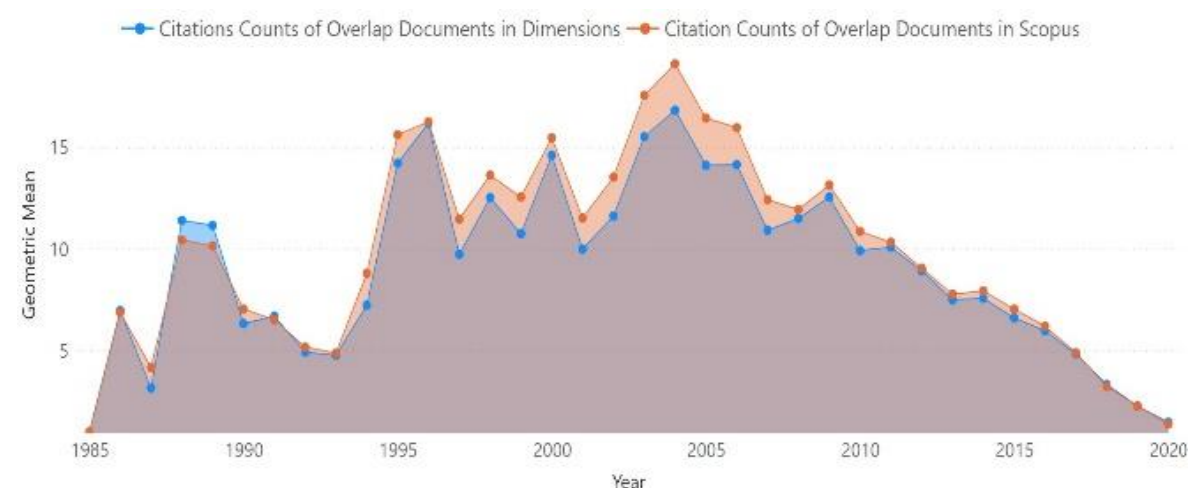

(b)

Figure 8. Geometric mean scores of citations for Dimensions and Scopus for (a) all documents, (b) documents overlap 
A similar linear increase in the coverage of citation counts in Dimensions comparable to those of Scopus. There is a remarkably high relationship between Dimensions and Scopus's citation counts for publications indexed in both. This study indicates that citation counts are closely related between Dimensions and Scopus, reflected in the respective scatterplots as shown in Figure 9.

\section{Scatter Plot}

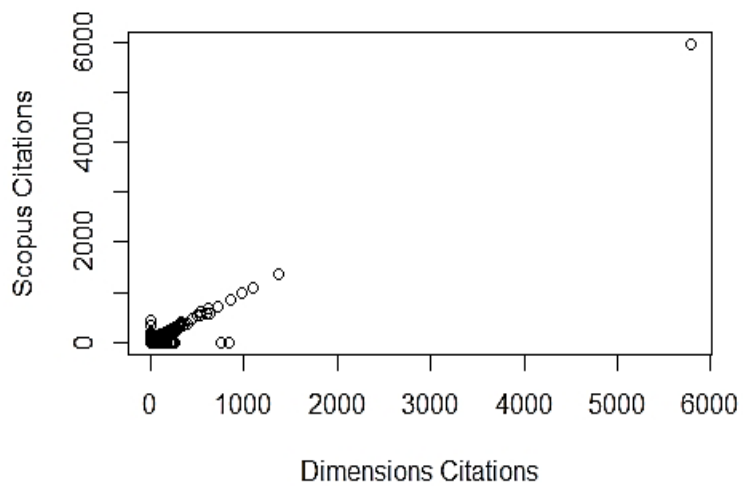

(a)

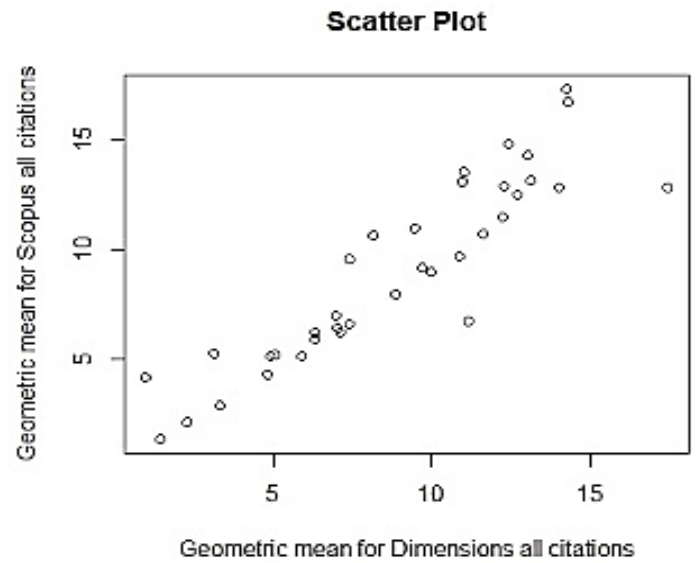

(c)

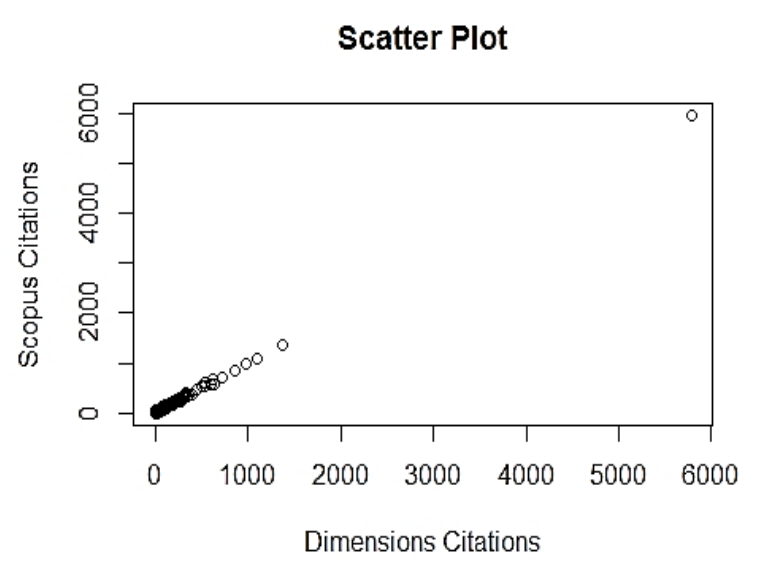

(b)

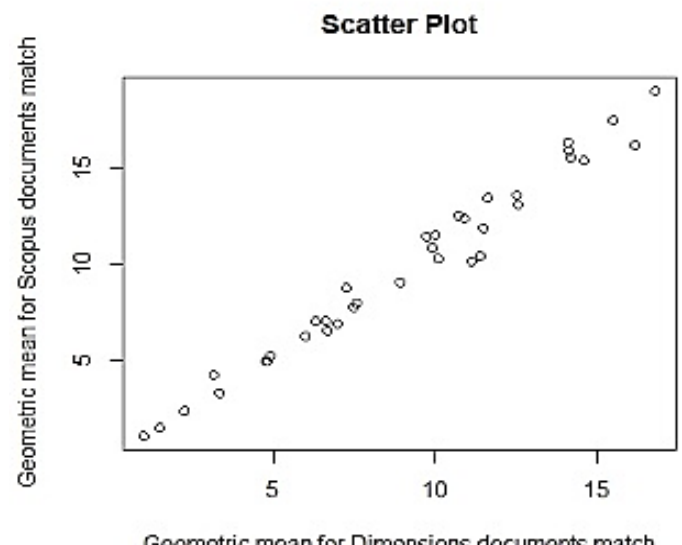

(d)

Figure 9. Scatter plot of (a) all Dimensions citations against Scopus citations, (b) the number of documents match by Dimensions against Scopus, (c) geometric mean citation counts of all documents in Dimensions against Scopus, and (d) geometric mean citation counts of documents match by Dimensions against Scopus

\subsection{Are citation counts of scholarly documents in Dimensions interchangeable with Scopus in terms of having a too high correlation?}

Spearman correlations between Dimensions and Scopus' citation counts ranged from 0.93 to 0.99 during 1986-2020 as shown in Table 5. The Spearman correlation coefficients are over 0.90 except one in 2020, which is 0.86 . This study suggested that correlations between Dimensions and Scopus are strong. The weakest correlation is 0.86 in the year 2020, and the strongest is 0.99 over the past ten years, i.e., 2016, 2015, 2014, 2012, and 2011.

Figure 10 showed the correlation between the citation counts of scholars' documents in Dimensions and Scopus based on the Pearson correlation coefficient and the Spearman correlation coefficient. As shown in Figure 10(a), the correlation between Dimensions and Scopus document citation counts was 0.9985, and the correlation between Dimensions and Scopus geometric mean citation counts was 0.9768 as shown in Figure 10(b) based on the Spearman correlation coefficient at a significant 0.01 level. This correlation shows a positive relationship and a strong correlation between the two databases. This evidence corresponds to the results of other studies [7], [9], [13], [15], [29], [34]-[37]. These findings match the results found in [21]. It can be concluded that Dimension and Scopus are exchangeable as citation data sources in terms of coverage and citation counts [21]. 
Table 5. The correlation between the number of citations in Dimensions and Scopus is based on the Spearman correlation coefficient

\begin{tabular}{|c|c|c|c|c|}
\hline Year & $\begin{array}{c}\text { Spearman correlation } \\
\text { coefficients* }(r)\end{array}$ & $\begin{array}{c}\text { Geometric mean } \\
\text { Dimensions }\end{array}$ & $\begin{array}{c}\text { Geometric } \\
\text { mean Scopus }\end{array}$ & $\begin{array}{c}\text { Geometric mean of } \\
\text { Dimensions }{ }^{\|} \text {Scopus }\end{array}$ \\
\hline 1986 & 0.941395052 & 6.97 & 6.87 & 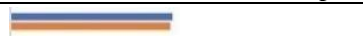 \\
\hline 1987 & 0.93027147 & 3.16 & 4.17 & 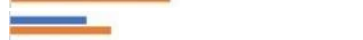 \\
\hline 1988 & 0.994680977 & 11.40 & 10.44 & \\
\hline 1989 & 0.97954658 & 11.16 & 10.15 & \\
\hline 1990 & 0.976437981 & 6.33 & 7.04 & 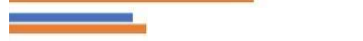 \\
\hline 1991 & 0.988915792 & 6.69 & 6.52 & 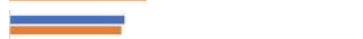 \\
\hline 1992 & 0.960226722 & 4.92 & 5.17 & 플 \\
\hline 1993 & 0.97891264 & 4.77 & 4.88 & ב \\
\hline 1994 & 0.998179446 & 7.23 & 8.80 & 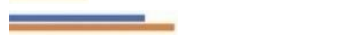 \\
\hline 1995 & 0.991522684 & 14.21 & 15.62 & \\
\hline 1996 & 0.982248558 & 16.18 & 16.25 & \\
\hline 1997 & 0.980228722 & 9.74 & 11.47 & 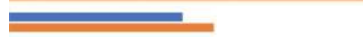 \\
\hline 1998 & 0.980223286 & 12.53 & 13.63 & 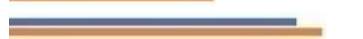 \\
\hline 1999 & 0.983241177 & 10.75 & 12.56 & ב \\
\hline 2000 & 0.989660197 & 14.60 & 15.47 & 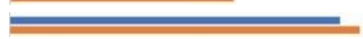 \\
\hline 2001 & 0.991868361 & 9.99 & 11.52 & 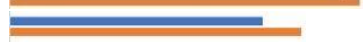 \\
\hline 2002 & 0.998788446 & 11.62 & 13.53 & 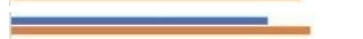 \\
\hline 2003 & 0.986946466 & 15.52 & 17.55 & $=$ \\
\hline 2004 & 0.991812391 & 16.82 & 19.10 & 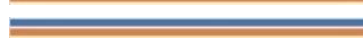 \\
\hline 2005 & 0.991224402 & 14.12 & 16.44 & 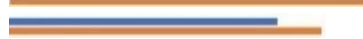 \\
\hline 2006 & 0.994004436 & 14.15 & 15.96 & $=$ \\
\hline 2007 & 0.996193088 & 10.92 & 12.42 & = \\
\hline 2008 & 0.99193793 & 11.49 & 11.94 & 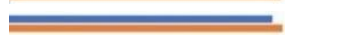 \\
\hline 2009 & 0.999892631 & 12.56 & 13.14 & \\
\hline 2010 & 0.9987192 & 9.92 & 10.86 & 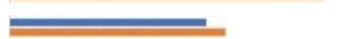 \\
\hline 2011 & 0.997639859 & 10.08 & 10.33 & 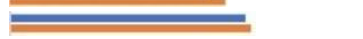 \\
\hline 2012 & 0.997114912 & 8.92 & 9.05 & 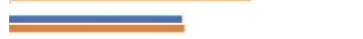 \\
\hline 2013 & 0.983240018 & 7.49 & 7.77 & 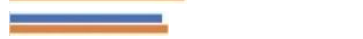 \\
\hline 2014 & 0.998500317 & 7.58 & 7.93 & ב \\
\hline 2015 & 0.998713079 & 6.61 & 7.04 & ב \\
\hline 2016 & 0.992948008 & 5.97 & 6.20 & ב \\
\hline 2017 & 0.973731637 & 4.84 & 4.89 & ב \\
\hline 2018 & 0.980075241 & 3.33 & 3.24 & $\overline{\underline{ }}$ \\
\hline 2019 & 0.980546973 & 2.27 & 2.27 & $=$ \\
\hline 2020 & 0.861211192 & 1.47 & 1.39 & 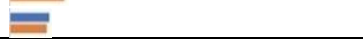 \\
\hline
\end{tabular}

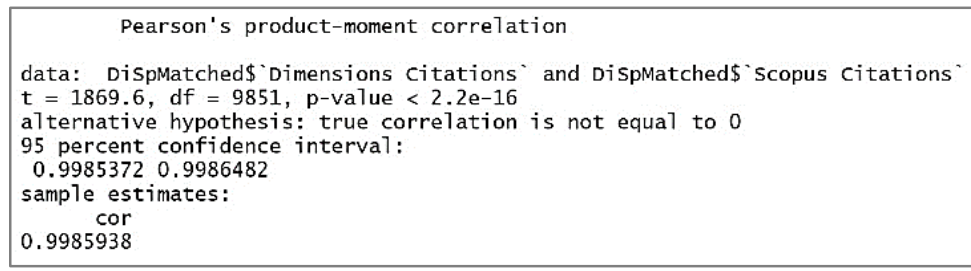

(a)

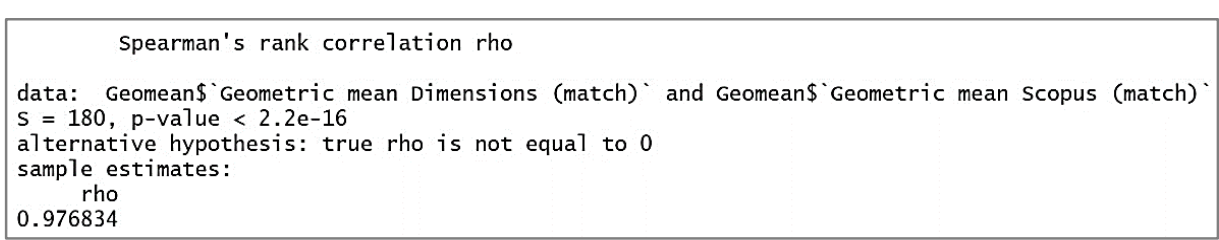

(b)

Figure 10. The correlation between the citation counts of scholars' documents in Dimensions and Scopus by:

(a) the Pearson correlation coefficient, (b) the Spearman correlation coefficient

\section{LIMITATIONS AND FURTHER RESEARCH}

There are a few drawbacks to this research. First, the researchers used a strict and conservative matching technique to prevent false positives. A few articles are spelled differently in separate lists not captured by our matching protocol. Second, the research study focused exclusively on analyzing the coverage of two different databases in PSU research publications, and the analysis of other kinds of publications such 
as books and conferences were not in the comparative scope. This study might be an interesting future work in analyzing how much books and conferences cover both databases. Also, the Web of Science was not part of the study. It can be taken as a work for the future [9]. Moreover, to make it more helpful to researchers for the importance of citations for the researchers' reputation, the interesting future work can be considered a motivation model for top-quality publications in [28], [27] as a new motivational driver in existing literature models.

This analysis created a portrait of Dimensions and Scopus journal coverage based on PSU's research productivity. According to the findings, Dimensions and Scopus' journal scope in the Humanities and Social Sciences is still very limited [9]. Further study should examine whether national publications that concentrate on local issues are well reflected in Dimensions and Scopus in the Humanities and Social Sciences. This research also focused on using specific data sources to solve citation-based ranking. This research could examine how bibliographic sources affect various performance evaluations, including citations as a performance metric.

University ranking is considered a measure of quality, effectiveness, and the universities' research performance [9], [38]. Further studies might need to compare citation data and the coverage of Dimensions and Scopus of a sample of scholars in different research fields. Additionally, future research scope might examine and compare samples from other institutions or other countries to a more accurate assessment of scholars' impact. Moreover, as the importance of citations for the researchers' reputations is one of the most important for researchers' future publishing [27], [28], future work might add a theoretical framework motivation model for top-quality publications to existing models to encourage researchers to publish highquality journals.

\section{CONCLUSION}

As reflected in this study's results on the same population of documents, Scopus can recover several citations exceeding Dimensions. However, the number of citations per publication in Dimensions slightly higher than in Scopus. Also, the analysis was made on articles published by PSU researchers. In this sense, Scopus includes more scholars' publications than Dimensions in scopes of coverage and citation counts correlation. Based on citations per publication, the number of citations per publication in Scopus is 13.01, but it is 13.35 citations per publication for Dimensions. However, the findings show that the number of citations per publication decreases in Dimensions and Scopus from 2010 to 2020.

Regarding the percentage of cited publications in Table 3, about $79 \%$ of Scopus's total publications are cited, while this percentage in Dimensions is about 78\%. It is noteworthy that, under review, the number of cited publications in Dimensions and Scopus has increased over the years. The number of non-cited publications is increasingly growing in both citation databases. The growth rate of scholars' publications in Dimensions is more than Scopus. The exponential regression test findings show a $15.32 \%$ annual growth rate in Dimensions for scholars' publications and a 14.85\% annual growth rate in Scopus. For this finding, a possible explanation could be that Dimensions covers substantially more publications than Scopus.

Although Dimensions has more excellent raw coverage of documents than Scopus, almost half of the Dimensions documents lack details on a country or institutional affiliation. Concerning findings in Table 4, although Dimensions and Scopus contain errors such as duplicate documents and citations and incomplete and incorrect bibliographic details, these problems do not seem to be a concern for this study because the authors justify dismissing citation counts as inaccurate due to the bibliographic errors found in Dimensions and Scopus.

The findings show that Dimensions and Scopus citation counts are significantly related, regardless of the difference in the number and average of citations. The results indicate that a positive correlation between the two citation databases is not entirely apart and has similarities. Spearman correlations between Dimensions and Scopus citation counts are robust. Thus, Dimensions seems to be substantially compatible with Scopus regarding coverage and citation counts.

Dimensions increase the number of citations per publication slightly higher Scopus (RQ1). The Dimensions scholarly database seems nearly equivalent to Scopus for citation analysis (RQ2). Moreover, Citation counts from scholarly database Dimensions correlate positively with Scopus (RQ3 and RQ4). Thus, using Dimensions and Scopus and other bibliographic tools helps researchers have a more complete and precise information retrieval and provides the possible grounds for doing a more comprehensive assessment of the quantity and quality of publications. Dimensions would be a helpful tool for researchers not to access expensive Scopus.

The number of publications and citation counts, Dimensions, and Scopus's use reveals a more comprehensive and the extent of the institution's scholarly productivity regarding the findings from the evaluation standpoint. This situation mainly affects Dimensions' possibilities as instruments for carrying out 
bibliometric analyses at university members' research productivity. These considerations are highly pragmatic for knowledge collection and policy formulation to use scientific databases as part of research assessment.

This research might support the university libraries' services and increase universities' research productivity. Following are some recommendations that the universities can implement to increase the research productivity: i) to increase university awareness of ranking structures and the value of study performance and citations to achieve higher rankings, ii) educate the university community about the publications indexed by Scopus and Dimensions, which feed data into rating systems, in order to maximize the amount of research published in them, iii) rise researchers' understanding of Bibliometrics and Altmetrics, as well as their effect on increased citations, iv) provide free access to knowledge services, analysis methods, and data management for research, and v) encourage researchers to use their university affiliations to establish their Research Identities through several channels, such as ResearchGate, ORCID, and others. Both data sources have concerns with inconsistency and inaccuracy with prospective bibliometric studies. However, we hope that this analysis will further advance this method and this data in the future.

\section{REFERENCES}

[1] D. W. Aksnes and G. Sivertsen, "A Criteria-based assessment of the coverage of Scopus and Web of Science," in Journal of Data and Information Science, vol. 4, no. 1, pp. 1-21, 2019, doi: 10.2478/jdis-2019-0001.

[2] J. Baas, M. Schotten, A. Plume, G. Côté, and R. Karimi, "Scopus as a curated, high-quality bibliometric data source for academic research in quantitative science studies," in Quantitative Science Studies, vol. 1, no. 1, pp. 377-386, 2020, doi: 10.1162/qss_a_00019.

[3] N. Boshoff and M. A. Akanmu, "Scopus or web of Science for a bibliometric profile of pharmacy research at a Nigerian university?," Journal South African Journal of Libraries and Information Science, vol. 83, no. 2, 2017, doi: 10.7553/83-2-1682.

[4] M. A. Erfanmanesh and F. Didegah, "A comparison of Web of Science and Scopus for Iranian publications and citation impact," International Journal of Information Science and Management (IJISM), vol. 11, no. 1, pp. 11-27, 2013. Accessed: Sep. 17, 2020. [Online]. Available: https://ijism.ricest.ac.ir/index.php/ijism/article/view/200

[5] G. G. Moghaddam, H. Jafari, and A. Sattarzadeh, "Publications by faculty members indexed in science citation index and Scopus: An Iranian case study," The Electronic Library, vol. 35, no. 6, pp. 1247-1258, Jan. 2017, doi: 10.1108/EL-04-2016-0102.

[6] M. R. Ghane and L. Mozafari, "A study of the subject of public libraries in Web of Science and Islamic World Science Citation Center," International Journal of Information Science and Management (IJISM), vol. 18, no. 1, pp. 35-48, 2020. Accessed: Sep. 17, 2020. [Online]. Available: https://ijism.ricest.ac.ir/index.php/ijism/article/view/1594

[7] A. Martín, E. O. Malea, M. Thelwall, and E. D. L. Cózar, "Google Scholar, Web of Science, and Scopus: A systematic comparison of citations in 252 subject categories," in Journal of Informetrics, vol. 12, no. 4, pp. 1160-1177, 2018, doi: 10.1016/j.joi.2018.09.002.

[8] H. F. Moed, F. de M. Anegon, V. G. Bote, and C. L. Illescas, "Are nationally oriented journals indexed in Scopus becoming more international? The effect of publication language and access modality," Journal of Informetrics, vol. 14, no. 2, May 2020, Art. no. 101011, doi: 10.1016/j.joi.2020.101011.

[9] P. Mongeon and A. P. Hus, "The journal coverage of Web of Science and Scopus: a comparative analysis," Scientometrics, vol. 106, no. 1, pp. 213-228, Jan. 2016, doi: 10.1007/s11192-015-1765-5.

[10] E. O. Malea, S. Aytac, and C. Y. Tran, "Universities through the eyes of bibliographic databases: a retroactive growth comparison of Google Scholar, Scopus and Web of Science," Scientometrics, vol. 121, no. 1, pp. 433-450, Oct. 2019, doi: 10.1007/s11192019-03208-7.

[11] M. Salajegheh and S. Dayari, "Comparing the citations counts and altmetrics of the top medical science journals in Scopus," International Journal of Information Science and Management (IJISM), vol. 17, no. 1, Jan. 2019, Art. no. 59. Accessed: Sep. 17, 2020. [Online]. Available: https://ijism.ricest.ac.ir/index.php/ijism/article/view/1384

[12] Q. Wang and L. Waltman, "Large-scale analysis of the accuracy of the journal classification systems of Web of Science and Scopus," in Journal of Informetrics, vol. 10, no. 2, pp. 347-364, 2016, doi: 10.1016/j.joi.2016.02.003.

[13] J. Zhu and W. Liu, "A tale of two databases: the use of Web of Science and Scopus in academic papers," in Scientometrics, vol. 123 , no. 1, pp. 321-335, 2020, doi: 10.1007/s11192-020-03387-8.

[14] A. A. Chadegani et al., "A Comparison between two main academic literature collections: Web of Science and Scopus databases," in Asian Social Science, vol. 9, no. 5, 2013, Art. no. 5, doi: 10.5539/ass.v9n5p18.

[15] A. W. Harzing, "Two new kids on the block: How do Crossref and Dimensions compare with Google Scholar, Microsoft Academic, Scopus and the Web of Science?" in Scientometrics, vol. 120, no. 1, pp. 341-349, 2019, doi: 10.1007/s11192-01903114-y.

[16] J. Adams, H. Draux, P. Jones, I. Osipov, S. Porter, and M. Szomszor, "Dimensions: a collaborative approach to enhancing research discovery," Digital Science, 2018. Accessed: Sep. 17, 2020. [Online]. Available: https://www.digitalscience.com/resources/portfolio-reports/dimensions-collaborative-approach-enhancing-research-discovery/

[17] R. W. Mouratidis, "Dimensions," in Journal of the Medical Library Association, vol. 107, no. 3, 2019, doi: 10.5195/jmla.2019.695.

[18] C. Herzog, D. Hook, and S. Konkiel, "Dimensions: Bringing down barriers between scientometricians and data," in Quantitative Science Studies, vol. 1, no. 1, pp. 387-395, 2020, doi: 10.1162/qss_a_00020.

[19] D. W. Hook, S. J. Porter, and C. Herzog, "Dimensions: Building Context for Search and Evaluation," Frontiers in Research Metrics and Analytics, vol. 3, 2018, doi: 10.3389/frma.2018.00023.

[20] E. O. Malea and E. D. L. Cózar, "Dimensions: re-discovering the ecosystem of scientific information," in arXiv preprint, vol. 27, no. 2, pp. 420-431, 2018, doi: 10.3145/epi.2018.mar.21.

[21] M. Thelwall, "Dimensions: A competitor to Scopus and the Web of Science?" in Journal of Informetrics, vol. 12, no. 2, pp. 430-435, 2018, doi: 10.1016/j.joi.2018.03.006.

[22] M. Thelwall and P. Wilson, "Regression for citation data: An evaluation of different methods," in Journal of Informetrics, vol. 8, no. 4, pp. 963-971, 2014, doi: 10.1016/j.joi.2014.09.011. 
[23] M. Thelwall, "Interpreting correlations between citation counts and other indicators," in Scientometrics, vol. 108, no. 1, pp. 337-347, 2016, doi: 10.1007/s11192-016-1973-7.

[24] H. T. Y. Achsan, H. Suhartanto and W. C. Wibowo, "A Technique in information retrieval and bibliometrics to check the reliability of an article indexing," 2019 International Conference on contemporary Computing and Informatics (IC3I), 2019, pp. 148-153, doi: 10.1109/IC3I46837.2019.9055651.

[25] G. Abramo, D. W. Aksnes, and C. A. D'Angelo, “Comparison of research performance of Italian and Norwegian professors and universities," Journal of Informetrics, vol. 14, no. 2, May 2020, Art. no. 101023, doi: 10.1016/j.joi.2020.101023.

[26] D. W. Aksnes, L. Langfeldt, and P. Wouters, "Citations, citation indicators, and research quality: An overview of basic concepts and theories," in SAGE Open, vol. 9, no. 1, 2019, Art. no. 2158244019829575, doi: 10.1177/2158244019829575.

[27] M. Lambovska and K. Yordanov, "Motivation of researchers to Publish in high-quality Journals: A theoretical framework," TEM Journal, vol. 9, no. 1, pp. 188-197, 2020, doi: 10.18421/TEM91-27.

[28] M. Lambovska and D. Todorova, "Publish and Flourish' instead of 'Publish or Perish': A motivation model for top-quality publications," Journal of Language and Education, vol. 7, no. 1, 2021, Art. no. 1, doi: 10.17323/jle.2021.11522.

[29] M. Visser, N. J. V. Eck, and L. Waltman, "Large-scale comparison of bibliographic data sources: Scopus, Web of Science, Dimensions, Crossref, and Microsoft Academic," pp. 29, 2019, arXiv:2005.10732.

[30] V. K. Singh, P. Singh, M. Karmakar, J. Leta, and P. Mayr, "The journal coverage of Web of Science, Scopus and Dimensions: A comparative analysis," in Scientometrics, 2021, doi: 10.1007/s11192-021-03948-5.

[31] T. Silwattananusarn, P. Kulkanjanapiban, Apr. 5, 2021. "DimensionsVSScopus_CorrelationalStudy," Figshare. Dataset. doi: 10.6084/m9.figshare.13718368.v1.

[32] S. A. S. AlRyalat, L. W. Malkawi, and S. M. Momani, "Comparing bibliometric analysis using PubMed, Scopus, and Web of science databases," in Journal of Viualized Expperiment, no. 152, 2019, doi: 10.3791/58494.

[33] V. P. G. Bote, Z. C. Rodríguez, A. Mendoza, and F. d. M. Anegón, "Comparative analysis of the bibliographic data sources Dimensions and Scopus: An approach at the Country and Institutional levels," in Frontiers Ressearch Metrics and analytics, vol. 5, 2021, doi: 10.3389/frma.2020.593494.

[34] A. Martín, E. O. Malea, and E. D. L. Cózar, "Coverage of highly-cited documents in Google Scholar, Web of Science, and Scopus: a multidisciplinary comparison," in Scientometrics, vol. 116, no. 3, pp. 2175-2188, 2018, doi: $10.1007 / \mathrm{s} 11192-018-2820-9$.

[35] J. Trapp, "Web of Science, Scopus, and Google Scholar citation rates: a case study of medical physics and biomedical engineering: what gets cited and what doesn't?," Australasian Physical \& Engineering Sciences in Medicine, vol. 39, no. 4, pp. 817-823, 2016, doi: 10.1007/s13246-016-0478-2.

[36] S. E. Hug and M. P. Brändle, "The coverage of Microsoft Academic: analyzing the publication output of a university," in Scientometrics, vol. 113, no. 3, pp. 1551-1571, 2017, doi: 10.1007/s11192-017-2535-3.

[37] A. Martín, M. Thelwall, E. O. Malea, and E. D. L. Cózar, "Google Scholar, Microsoft Academic, Scopus, Dimensions, Web of Science, and OpenCitations' COCI: a multidisciplinary comparison of coverage via citations," in Scientometrics, vol. 126, pp. 871-906, 2021, doi: 10.1007/s11192-020-03690-4.

[38] D. T. Salinas, E. D. L. Cózar, and E. J. Contreras, "Ranking of departments and researchers within a university using two different databases: Web of Science versus Scopus," in Scientometrics, vol. 80, no. 3, pp. 761-774, 2009, doi: 10.1007/s11192-008-2113-9.

\section{BIOGRAPHIES OF AUTHORS}

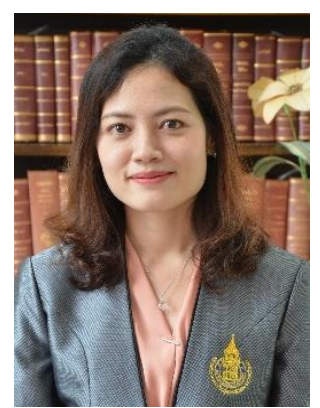

Pachisa Kulkanjanapiban (D) $8 \mathrm{SC}$ S $\mathrm{P}$ is an Academic Librarian with a Professional Level in the Khunying Long Athakravisunthorn Learning Resources Center, Prince of Songkla University, Thailand. She holds a M.Sc. degree in Management Information Technology (MIT) from the Prince of Songkla University. She is a specialist in scientometrics, bibliometrics, and predictive modelling. Her expertise is Institutional Repository (IR), especially running the "PSU Knowledge Bank." Also, she has been teaching the course in Information Technology and Information Systems in Libraries and Information Learning Centers. She is fascinated by data analytics and visualization, business intelligence, database analysis and design, information management systems, digital information management, and data management topics. She can be contacted at email: pachisa.ku@ psu.ac.th.

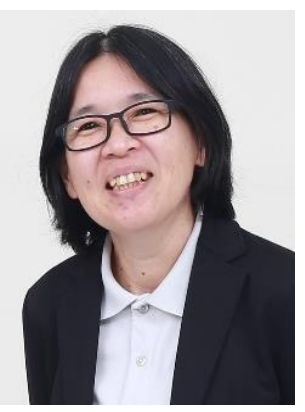

Tipawan Silwattananusarn (D) $\mathrm{SC}$ S $\mathrm{P}$ is an Assistant Professor in the Information Management Program, Faculty of Humanities and Social Sciences, Prince of Songkla University, Thailand. She has received her Ph.D. degree in Information Studies from Khon Kaen University. She is involved in research and teaching in Data Mining and Machine Learning Tools, Data Analytics and Visualization, Information Systems and Technologies, Information Security Management, Digital Information Management, Information Management System. She is a specialist in data mining and analytics, data mining in academic libraries, data mining and its applications for knowledge management, and IT applications in academic libraries. She can be contacted at email: tipawan.s@psu.ac.th. 